\title{
Persistency of Turkish export shocks: a quantile autoregression (QAR) approach
}

\author{
M. Hakan Berument ${ }^{1} \cdot$ N. Nergiz Dincer ${ }^{2}$ • \\ Pinar Yasar ${ }^{3}$
}

\begin{abstract}
This study analyzes the persistency of total and disaggregated Turkish exports for different shock magnitudes using the quantile autoregression (QAR) method in line with Koenker and Xiao (J Am Stat Assoc 99:775-787, 2004). The results suggest that the persistence of shocks are not similar across different quantiles of Total Exports and disaggregated export sectors, indicating an asymmetry in the case of negative and positive shocks across different export sectors. The persistency behavior of Total Exports as well as Food and Beverages, Chemicals, Basic Metals, Raw Materials, Motor Vehicles and Radio \& TV exports are asymmetric to negative versus positive shocks, which cannot be captured by traditional unit root tests. Thus, sound interpretation of QAR results is necessary for policy makers to identify shock characteristics and thereby pursue appropriate policies for overcoming adverse impacts on the economy.
\end{abstract}

Keywords Export demand · Unit root · Quantile autoregression

The views presented here are those of the author; they do not necessarily reflect the official position of the Ministry of Development.

$\triangle$ M. Hakan Berument berument@bilkent.edu.tr;

http://www.bilkent.edu.tr/ berument

N. Nergiz Dincer

nergiz.dincer@tedu.edu.tr

Pinar Yasar

pinar.yasar@kalkinma.gov.tr

1 Department of Economics, Bilkent University, 06800 Ankara, Turkey

2 Department of Economics, TED University, 06420 Ankara, Turkey

3 Economic Modeling Department, Ministry of Development and Department of Economics, Hacettepe University, 06100 Ankara, Turkey 
JEL Classification $\mathrm{F} 14 \cdot \mathrm{F} 11 \cdot \mathrm{C} 32$

\section{Introduction}

Turkey has been following an export-led growth strategy since trade liberalization was implemented in the 1980s. Exports have played a major role in the economy's overall performance and, especially in the first part of the $2000 \mathrm{~s}$, have become an important contributor to the achieved high growth rates. However, export performance has also been subject to external shocks triggered by crises, such as the financial crisis in 2008. Shock persistence is important for forecasting overall economic performance as well as for policy implications.

Unit root hypothesis and testing are useful tools to analyze shock persistency, and the literature on these methods extends back to the 1990s. In a pioneering study, Campbell and Perron (1991) note that the unit root issue revolves around whether regular shocks create a permanent effect on the series level. Perron and Vogelsang (1992) emphasize that the unit root hypothesis carries significant implications with respect to economic theory and evaluating empirical evidence. While these findings are notable, for Turkish exports, shock magnitude might be more important for series persistency. After a negative shock, a product's market share may decrease so much that restoring the same export level may not be possible or may take a long time. After a positive shock, inventories may increase so much that to decrease them exports may need to be halted.

Income and exchange rate elasticities of different export sectors may also vary. Thus, different components of exports might be subject to different unit root characteristics. Few studies focus on sectoral exports, but of those, Dincer and Kandil (2011) document and estimate sectoral export functions in Turkey to explore the asymmetric impacts of real exchange rate shocks across different sectors. Their results suggest a positive and significant cumulative response to negative exchange rate shocks (undervaluation of the exchange rate) in five sectors, accounting for $23 \%$ of total exports, implying a reduction in export growth forced by the higher cost of imported inputs. Using a seemingly unrelated regression method, Berument et al. (2014) investigate and document shock distribution across Turkey's export sectors and the level of heterogeneity (or homogeneity) in the ongoing recovery following the 2008 crisis. Thus, shock persistence properties are different across different sectors; a positive shock after a certain threshold may trigger firms to make certain investment and employment decisions, depending on the specificity of a sector, so that the effect of a shock will be permanent. However, for lower levels of shock or for a negative shock firms may not change their production potential capabilities, and thus the effect of a shock may not be persistent, and the process will be mean-reverting. For these reasons, the effect of different magnitudes of shock on production/export performance will be different.

The objective of the current study is twofold: first, we assess export unit root characteristics for different shock magnitudes using the quantile autoregression (QAR) method, in line with Koenker and Xiao (2004). Second, we analyze total 
exports and each of the sectoral components separately and classify them according to their persistencies.

There is an extensive literature on the unit root characteristics of export sectors. Islam (1998) examines the exports of 15 Asian countries for the period 1967-1991. His results suggest that the underlying export series are non-stationary in levels but stationary in first differences. Kónya (2004) analyzes the exports of 25 OECD countries for the period 1960-1997. Although the traditional tests he uses produce conflicting results, overall, he finds the exports of most countries non-stationary. Lim et al. (2011) test the exports of Thailand, Malaysia, Indonesia and the Philippines for unit root using nonparametric econometric techniques, including the Breitung unit root test, and suggest that exports are not stationary in levels. Hoffmann et al. (2003) test the process of the unit root for 10 destination markets. The results reject the null of the unit root of three markets but they cannot reject it for the other seven. Thus, shocks to export demand have a permanent effect on seven markets and a transitory effect on three, suggesting that governments may wish to introduce policy initiatives to counter damages to the former markets. A set of studies tests Turkish exports for unit root using traditional techniques: Ozturk and Acaravci (2010) and Mangir (2012) analyze Turkish exports for the periods 1989-2006 and 2002-2011, respectively, using quarterly time series data. Both studies suggest the non-stationarity of Turkish exports. However, none of the abovementioned studies analyzes the persistency of external shocks in detail.

To the best of our knowledge, no studies in the literature focus on shock persistency on different quantiles and disaggregated export data, neither for Turkey nor for other economies. Considering this gap, this paper aims to elaborate on the persistency of disaggregated Turkish exports by taking shock magnitudes into consideration using the QAR method.

The common practice to test series persistence is to perform unit root tests. The issue with traditional unit root tests [such as the augmented Dickey-Fuller (ADF) test] is based on their use of ordinary least squares (OLS) estimations, which require normal distribution assumptions. Results from this method, however, can only describe averages in the overall data, thus, they can only concentrate on the conditional central tendency and lack a method of assessment under possible different mean-reverting behaviors of any series hit by different magnitudes and shock signs at different quantiles. Koenker and Xiao (2004) mention that particularly in the case of non-normality, commonly used unit root tests can display rather poor power performance, tending to bias results in favor of a unit root. In contrast, the QAR approach makes no assumptions about series distribution and considers the conditions of misspecification errors related to non-normality and the presence of outliers, thus it produces robust estimates.

Our results of the QAR analysis suggest that shock persistence is not similar across different quantiles or export sectors, whereas the traditional unit root test cannot reject the presence of the unit root for all export categories in levels, except for one. However, when asymmetry is allowed, the persistency behaviors of Total Exports as well as Food and Beverages, Chemicals, Basic Metals, Raw Materials, Motor Vehicles and Radio \& TV exports are asymmetric to negative and positive shocks. This characteristic cannot be captured by the traditional unit root test, thus, 
sound interpretation of QAR results is necessary for policy makers to identify shock characteristics and thereby pursue appropriate policies for overcoming their adverse impacts on the economy.

Section 2 discusses our methodology and Sect. 3 presents the data. Section 4 discusses the results and Sect. 5 concludes.

\section{Methodology}

In this section, we briefly describe the Quantile Autoregression approach, introduced and discussed by Koenker and Xiao (2002, 2004, 2006). This method allows direct analysis of how a past information set influences a time series' conditional distribution and enables exploring a series' unit root characteristics across different quantiles. By employing QAR, it is possible to carry out a unit root test at each quantile and to separate non-stationary observations from stationary ones. Quantile autoregression also relaxes the assumption of normal distribution, thereby offering a more flexible and refined time series analysis.

The QAR method also allows capturing asymmetric export adjustments towards a long-run equilibrium. In other words, it enables us to explore the speed of mean reversion for a series under different magnitudes and shock signs. This method enjoys power gains over the ADF test when the shock exhibits heavy-tailed behavior. Because of QAR's several useful properties, it has been begun to be widely used in the literature (Boengiu et al. 2011; Gomes 2011; Tsong and Lee 2011).

Consider an ADF-type regression model, such as the following:

$$
y_{t}=\beta_{1} y_{t-1}+\sum_{j=1}^{p} \beta_{j+1} \Delta y_{t-j}+u_{t} \quad \mathrm{t}=1,2, \ldots \mathrm{n}
$$

$u_{t}$ is the $i i d$ random variable with zero mean and constant variance. In the model, the autoregressive coefficient $\beta_{1}$ indicates the persistency of the time series $y_{t}$. If $\beta_{1}=1$, then $y_{t}$ contains a unit root and is persistent. If $\left|\beta_{1}\right|<1$, then $y_{t}$ is stationary and its behavior exhibits a mean reversion.

Let $\mathrm{Q} y_{t}$ be the $\tau$ th conditional quantile of $y_{t}$, conditional on the past information set, denoted as $\Psi_{\mathrm{t}-1}$, as the following:

$$
\mathrm{Q} y_{t}\left(\tau \mid \Psi_{t-1}\right)=x_{t}^{T} \beta(\tau)
$$

This representation is called the quantile autoregressive of order $p$ model, or $\operatorname{QAR}(p)$ model. In Eq. 2, $x_{t}=\left(1, y_{t-1}, \Delta y_{t-1}, \ldots, \Delta y_{t-p}\right)^{T}$ and $\beta(\tau)=\left(\beta_{0}(\tau)\right.$, $\left.\beta_{1}(\tau), \ldots, \beta_{p+1}(\tau)\right)^{T} . \beta(\tau)$ denotes the regression parameter of the $\tau$ th conditional quantile. Equation 2 refers to the $\tau$ th conditional quantile function of $y_{t}$, which is expressed as a linear functional equation with its own lagged and difference terms. Using the above equation, it is possible to test for several local behaviors of the stochastic process, such as the convergent pattern, the random walk and the explosive pattern, displayed by $y_{t}$. 
To estimate the linear QAR(p) model, the following objective function needs to be minimized:

$$
\min \sum_{t=1}^{n} \rho_{t}\left(y_{t}-x_{t}^{T} \beta(\tau)\right)
$$

$\rho_{t}$ is defined in Koenker and Basset (1978) as:

$$
\begin{aligned}
& \rho_{t}(u)=\tau u \quad \text { if } u \geq 0 \\
& \rho_{t}(u)=(\tau-1) u \quad \text { if } u<0
\end{aligned}
$$

The solutions of Eq. 3 are called quantile autoregressive estimators of order $p . \tilde{\beta}(\tau)$ refers to the estimated coefficients.

Given the solution to Eq. 3, the quantile unit root test involves a simple $t$ statistic test, which will enable us to test the time series properties of $y_{t}$ for each quantile. This test statistic also allows us in each quantile to analyze the meanreverting behavior of the series when exposed to different magnitudes and signs of shocks.

In addition to these analyses, Koenker and Xiao (2004) propose an approach called the Kolmogorov-Smirnov (KS) test to make a unit root test over a range of quantiles, $\tau \varepsilon \Gamma$, instead of concentrating on a selected quantile:

$$
\mathrm{QKS}=\sup \left|U_{n}(\tau)\right|
$$

where $U_{n}(\tau)$ is the coefficient based statistics given by

$$
U_{n}(\tau)=n(\tilde{\beta}(\tau)-1)
$$

\section{Data}

All export data are obtained from TURKSTAT Foreign Trade Statistics and Foreign Trade Indices databases. Nominal Turkish export data are two-digit in the ISIC Rev.3 classification and in the Broad Economic Categories (BEC) Classification on a monthly basis. The data set covers the period from 1996:1 to 2012:4. In the ISIC Rev.3 detail, nominal exports in dollar terms belong to the sectors of Food Products and Beverages (code:15), Textiles (code:17), Wearing Apparel (code:18), Chemicals and Chemical Products (code:24), Rubber and Plastic Products (code:25), Other Non-metallic Minerals (code:26), Manufacture of Basic Metals (code:27), Manufacture of Fabricated Metal Products excluding Machinery (code:28), Manufacture of Machinery and Equipment (code:29), Electrical Machinery and Apparatus (code:31), Communication and Apparatus (code:32), Motor Vehicles and Trailers (code:34) and Furniture (code:36), and in the BEC classification detail, Raw Material Goods, Consumption Goods and Investment Goods data are obtained from Foreign Trade Statistics database. The export prices of these sectors are taken from the Foreign Trade Indices database. Nominal exports are deflated using these 


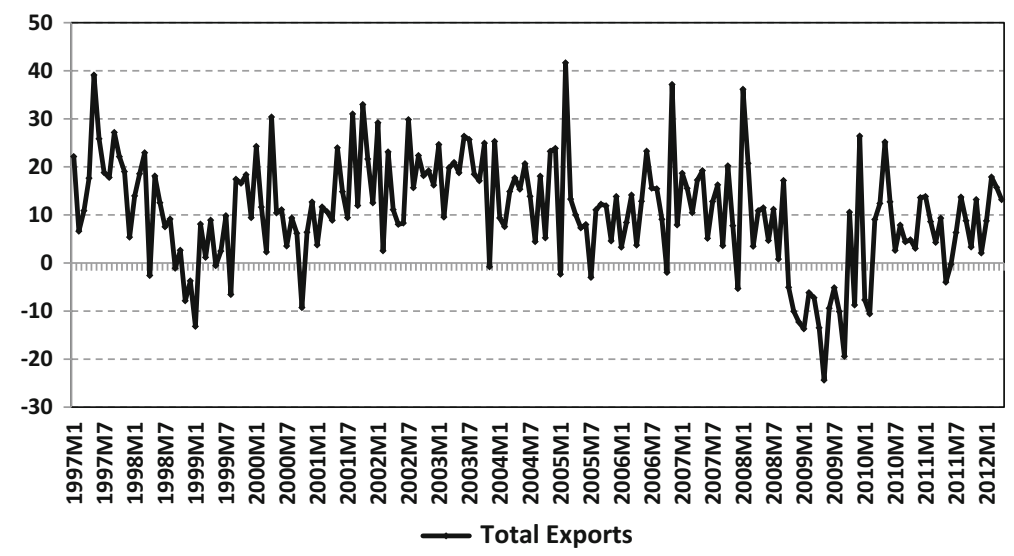

Fig. 1 Yearly change in real total exports (\%)

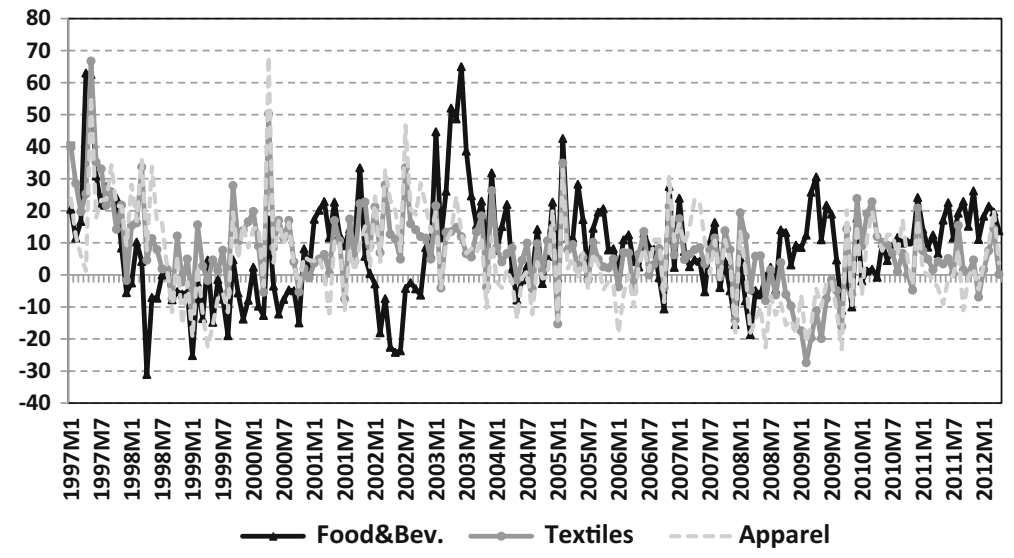

Fig. 2 Yearly change in real exports of Food and Bev., Textiles and Apparel (\%)

prices. Changes in total exports and all sub-categories in real terms are displayed in Figs. 1, 2, 3, 4 and 5. All the variables employed in the analyses are seasonally adjusted. ${ }^{1}$

\footnotetext{
1 The series that we employ are all seasonally adjusted. To account for seasonality we had two options. The first option was to use seasonally adjusted data, and the second was to address the seasonality within the equation. Quantile regression classifies equations/parameters with left-hand-side variables rather than right-hand-side variables. Employing the latter method may lead us to classify the variable more with the seasonal pattern than with outliers or higher levels of exports. Thus, following Koenker and Xiao (2004), we employ seasonally adjusted data in the analyses.
} 


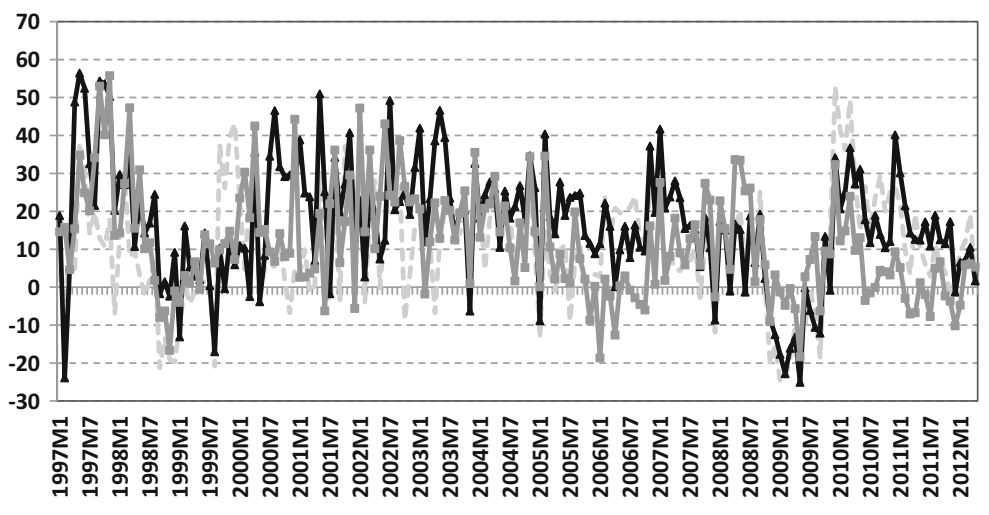

Chemicals

Rubber \& Plastic

Oth. Non-met. Mineral Product

Fig. 3 Yearly change in real exports of Chemicals, Rubber and Plastic and Oth. Non-met. Mineral Products $(\%)$

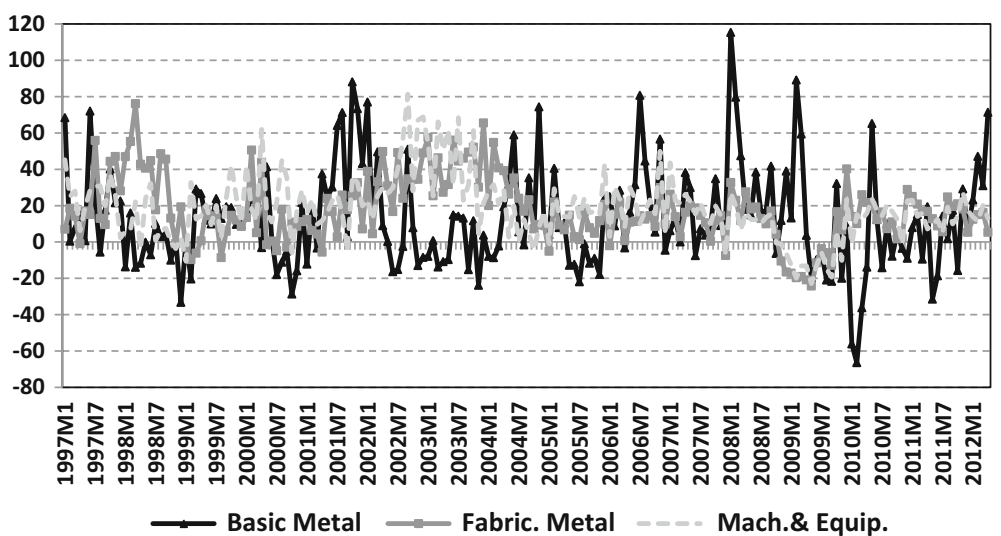

Fig. 4 Yearly change in real exports of Basic Metals, Fab. Metals and Mach. and Equip. (\%)

\section{Empirical results}

Table 1 reports the conventional unit root tests for the total exports and various export series in their logarithms. The ADF test cannot reject the null of the unit root for all series that we consider except Basic Metals. However, for all the series in their logarithmic differences that we consider, the null of the unit root is rejected. Thus, we may consider that all series except Basic Metals are I(1). ${ }^{2}$

\footnotetext{
${ }^{2}$ In this paper we consider the possibility that the persistence of shocks is asymmetric. Thus, we also perform a Lumsdaine-Papell unit root test with one and two breaks. The results for levels are mostly parallel to the ADF tests in Table 1, but we could also reject the null for Motor Vehicles and Textiles at the level. This finding supports the argument that series' persistency properties change with quantiles. The results of the Lumsdaine-Papell unit root tests are not reported here to save space.
} 


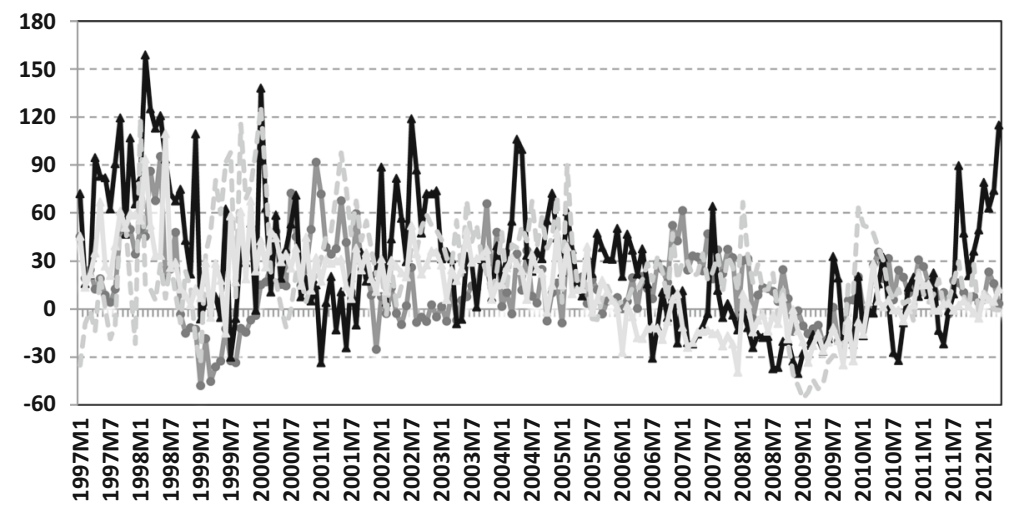

$\simeq$ Elec. Mach. — Radio \& TV ---- Motor Vehicles_ Furniture

Fig. 5 Yearly change in real exports of Elec. Mach., Radio \& TV, Motor Vehicles and Furniture (\%)

Table 1 Unit root test results of exports on a sectoral basis (2-digit)

\begin{tabular}{llc}
\hline & \multicolumn{2}{c}{ Augmented Dickey-Fuller (ADF) (1) } \\
\cline { 2 - 3 } & Level & First difference \\
\hline Total Exports & -1.75 & $-11.45^{* * *}$ \\
Food and Bev. & -1.95 & $-18.53^{* * *}$ \\
Textiles & -0.04 & $-21.48^{* * *}$ \\
Apparel & 0.02 & $-21.24^{* * *}$ \\
Chemicals & -2.57 & $-16.48^{* * *}$ \\
Rubber and Plastic & -2.30 & $-17.49^{* * *}$ \\
Oth. Non-met. Mineral Products & -1.81 & $-18.15^{* * *}$ \\
Basic Metals & $-6.13 * * *$ & $-11.67^{* * *}$ \\
Fabric. Metals & -2.20 & $-17.09^{* * *}$ \\
Mach. and Equip. & -1.36 & $-19.51^{* * *}$ \\
Elec. Mach. & -2.33 & $-17.54^{* * *}$ \\
Radio \& TV & -2.09 & $-13.38^{* * *}$ \\
Motor Vehicles & -2.19 & $-21.93^{* * *}$ \\
Furniture & -0.18 & $-15.43^{* * *}$ \\
Raw Materials & -2.24 & $-13.40^{* * *}$ \\
Consumption Goods & -1.29 & $-18.03^{* * *}$ \\
Investment Goods & -2.00 & $-15.20^{* * *}$ \\
\hline All Mables & &
\end{tabular}

All variables are in logarithmic forms

Schwartz Criteria (SC) were used for selecting the number of lags *, **, *** Significance at 10,5 and $1 \%$, respectively

(1) The null hypothesis of non-stationarity 


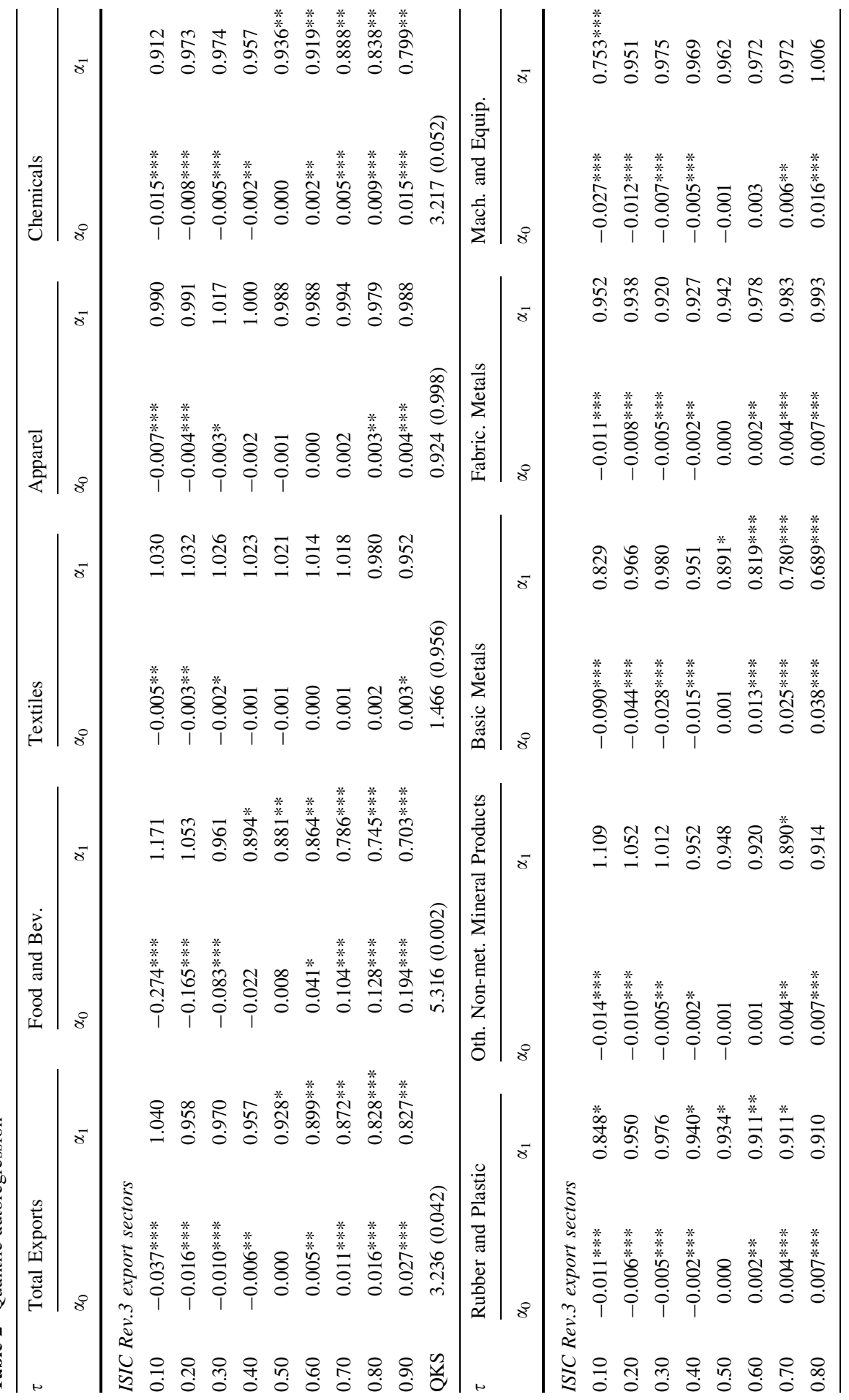




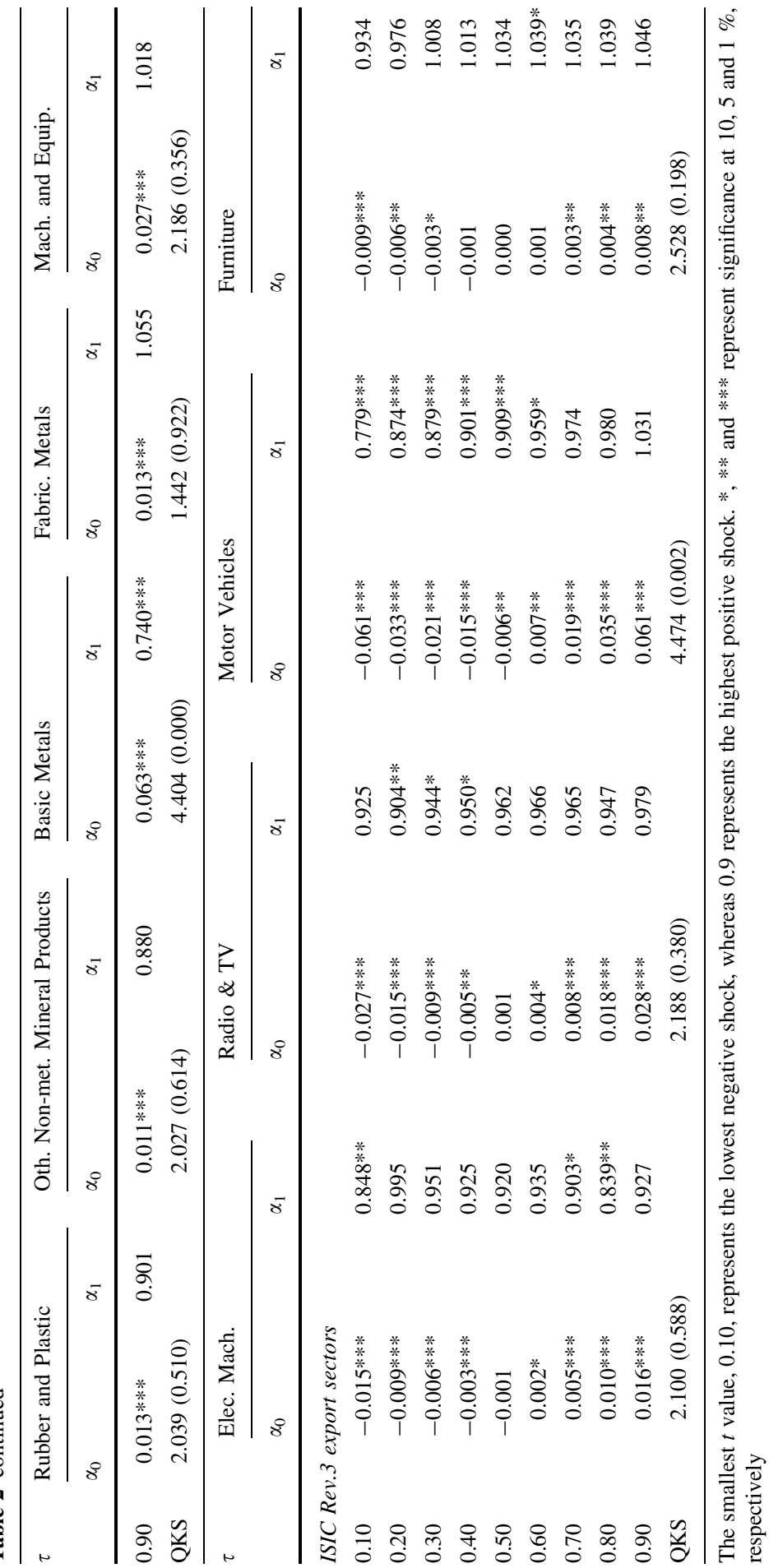


After performing the traditional unit root tests, we perform the QAR-based unit root tests. Table 2 reports the QAR results for $10 \%$ of the quantiles, which includes the quantile Kolmogorov-Smirnov (QKS) test results, the estimated values of $\alpha_{0}(\tau)$ and the autoregressive coefficient $\alpha_{1}(\tau)$ for each export category. The QKS tests provide a general perspective regarding the mean-reverting behavior of the series for different quantiles. Thus, for some series or for certain types of shocks, the effect will be permanent and the policy may not produce the optimum outcome.

Coefficient $\alpha_{0}$ captures the magnitude of the observed shock within the specific quantile that hits the exports. In our analysis, negative signs of $\alpha_{0}$ denote a negative shock, which might be the result of contracting foreign demand, substantial exchange rate movements or other shocks that would affect exports adversely. Similarly, positive signs denote positive shocks. The larger the values of $\tau$, the bigger the values of $\alpha_{0}(\tau)$ for each sector. Except for the Motor Vehicles sector, once the $\alpha_{0}$ coefficients are observed, at the 50th quantile the shock size is not significantly different from zero at the $5 \%$ significance level for all sectors. On the other hand, the size of shock varies across sectors; the most dispersive belongs to Food and Beverages, with those exports having the biggest and smallest shocks, from -0.274 to 0.194 .

The variable $\alpha_{1}$ in Table 2 provides unit root tests for different quantiles, and is thereby the main focus of our analysis. Examining $\alpha_{1}$ across export categories and quantiles, one observes that shock persistence is not similar among quantiles and disaggregated export sectors. The unit roots are rejected for some quantiles but not for others. However, the results of the traditional unit root test presented in Table 1 suggest that the presence of the unit root is rejected for all export categories. Looking at different quantiles for the unit root is important for analyzing shock persistence in negative and positive shocks, thereby differentiating policy implications. This characteristic cannot be captured by the traditional unit root test.

The results of the traditional unit root analysis and QAR approaches are similar only for Textiles, Apparel and Fabricated Metals. We cannot reject the null of the unit root across all quantiles in the QAR analysis, as in Table 2, nor for the traditional unit root analysis. The results of the QAR and ADF analyses vary in almost every sector other than these three, which is an indication of the drawbacks of traditional unit root methodology.

Table 2 suggests that for the Textiles and Apparel sectors, we cannot reject the unit root in each quantile, and thus these sectors have persistent behaviors. These sectors also face fierce global competition. Especially following China's accession to the World Trade Organization, Turkish textile and clothing sectors are under more pressure to preserve market shares. Thus, the impact of a market loss in these sectors would be long-lived. In the event of a positive shock, implying increasing demand for Turkish products, the impact would also be long-lived.

For the categories of Other Non-metallic Minerals and Furniture, we can reject the unit root only in one quantile, at the $10 \%$ level. We may also claim that we cannot reject the unit root for these two categories, or that shocks are permanent. For Fabricated Metals, we cannot reject the null of the unit root in every quantile. Thus, this sector displays persistent behavior under positive and negative shocks. 
Similar to the Textiles and Apparel sectors, in the event of a market loss or entering new markets, the impacts would be long-lived for the Fabricated Metals sector.

The difference between the implications of QAR and ADF is evident for Total Exports, Food and Beverages, Chemicals, Basic Metals and Raw Materials exports. We cannot reject the null of the unit root only for lower quantiles in these sectors in the QAR analysis; in other words, there is an asymmetry across quantiles that cannot be captured by ADF. The dynamic behavior of these sectors is asymmetric, meaning that while they have a unit root in lower quantiles, they do not have a unit root in upper quantiles. With positive signs in constant terms and non-unit root behavior in AR terms, with small $p$ values at higher quantiles, positive shocks to the aforementioned exports are short-lived. In the presence of negative shocks, exports display persistent behavior. This result might be interpreted as that negative shocks are persistent but positive shocks are short-lived. In other words, under an adverse shock, the export market can be lost; but as the demand for export product increases, this increase may not be permanent and exports in these markets for the corresponding product can be lost.

Considering the Food and Beverages sector, in which the unit root can be rejected at higher quantiles and cannot be rejected at lower quantiles, negative shocks to a long-lived structure can be attributed to some sector-specific characteristics. In these sectors, meeting the required product standards might be of crucial importance. For instance, for European Union (EU) membership, Turkey is supposed to be in harmony with EU norms and directives in terms of food standards. In recent years, dried figs exported by Turkey to the EU have been rejected due to high levels of aflatoxin, which has led to a substantial economic loss (Bircan and Koc 2012). Moreover, with product differentiation and market strategies, demand can shift easily among products. Last, producers' expectations and production plans may change rapidly in the event of a negative shock. On the other hand, especially in the Chemicals sector (of which Turkey is a net importer), the non-stationary behavior of exports in the event of a negative shock creates some risks and vulnerabilities for the economy. Considering Turkey's current account deficit, Chemicals imports follow energy imports in terms of their contribution to the deficit, constituting the second-largest item. Thus, long-lived negative shocks on a country's Chemicals exports should be well considered by policy makers.

The QAR method's most striking result belongs to the Motor Vehicles sector, which, along with Basic Metals, has the largest share of Turkish exports. We can reject the null of the unit root at lower quantiles; the findings imply that Motor Vehicles exports can revert to a steady-state level when a negative shock hits at lower quantiles but they display unit root behavior when a positive shock hits them at higher quantiles. This result can indicate that the local behavior of such exports would be more short-lived in the presence of a negative shock, such as weak foreign demand, than it would in the presence of positive shock, such as strong foreign demand.

For Machinery and Equipment exports, which constitute an important part of Turkish exports, we cannot reject the null of the unit root except in the first quantile. Therefore, when hit by a negative or a positive shock, this sector would not revert to its steady-state level because shocks tend to be permanent. There is no asymmetry in 
terms of the dynamic behavior of this export. On the other hand, Radio \& TV exports display a similar pattern to Motor Vehicles, ignoring the first quantile. Based on estimation results, in the presence of positive shocks, sector exports display persistent behavior, but in the presence of negative shocks they may revert to a steady state.

For Motor Vehicles, Radio \& TV and Machinery and Equipment exports the unit root exists at higher quantiles. Thus, under a positive shock, excess export demand will outlast itself due to vertical integration of these sectors with their export markets. Turkey's Motor Vehicles sector has attracted a significant amount of foreign investment, and because of Turkey's potential to improve its position in the sector's global production, policy makers should definitely focus on this area. If Turkey follows a strategy to invest in the aforementioned export categories, it can considerably increase its export potential, which would considerably contribute to a sustainable growth process. Moreover, because sectors such as Motor Vehicles are not traditional, they have high added value, which can be further increased by additional investment in $\mathrm{R} \& \mathrm{D}$.

For Rubber and Plastic, the unit root can be rejected at the $5 \%$ significance level only at the 60th quantile. Thus, we may claim that positive and negative shocks have persistent effects. For Electrical Machinery, unit roots can be rejected at the 10 and $80 \%$ quantiles at the $5 \%$ significance level. Thereby, it seems that a permanent effect presents at the middle quantile but a short-lived impact exists at higher quantiles.

Table 3 reports the QAR analysis for the following three goods categories in the BEC classification: Raw Materials, Consumption Goods and Investment Goods. For all categories, considering $\alpha_{0}$ estimates, shock size is not significantly different from zero at the $5 \%$ significance level for all sectors at the 50th quantile, but it varies across categories. The largest positive shock belongs to Raw Materials, with a value of 0.14 , and the largest negative shock belongs to Consumption Goods, with a value of -0.171 .

Table 3 Quantile autoregression: BEC export classification

\begin{tabular}{|c|c|c|c|c|c|c|}
\hline \multirow[t]{2}{*}{$\tau$} & \multicolumn{2}{|c|}{ Raw Materials } & \multicolumn{2}{|c|}{ Consumption Goods } & \multicolumn{2}{|c|}{ Investment Goods } \\
\hline & $\alpha_{0}$ & $\alpha_{1}$ & $\alpha_{0}$ & $\alpha_{1}$ & $\alpha_{0}$ & $\alpha_{1}$ \\
\hline 0.10 & $-0.153 * * *$ & 1.161 & $-0.171 * * *$ & $1.181^{*}$ & $-0.069 * * *$ & 1.011 \\
\hline 0.20 & $-0.07 * * *$ & 1.02 & $-0.108 * * *$ & $1.098^{*}$ & $-0.038 * * *$ & 0.933 \\
\hline 0.30 & $-0.046^{* * *}$ & 0.966 & $-0.071 * * *$ & 1.064 & $-0.024 * * *$ & 0.916 \\
\hline 0.40 & $-0.025^{* *}$ & 0.954 & -0.019 & 0.987 & $-0.01 * *$ & 0.947 \\
\hline 0.50 & -0.005 & 0.944 & 0.016 & $0.954^{*}$ & -0.001 & 0.96 \\
\hline 0.60 & $0.026 * * *$ & $0.876^{* * *}$ & $0.044 * * *$ & $0.906 * * *$ & $0.01 * *$ & 0.942 \\
\hline 0.70 & $0.056 * * *$ & $0.828 * * *$ & $0.062^{* * * *}$ & $0.891 * * *$ & $0.021 * * *$ & 0.939 \\
\hline 0.80 & $0.09 * * *$ & $0.762 * * *$ & $0.083^{* * *}$ & $0.875^{* * *}$ & $0.033^{* * *} *$ & 0.933 \\
\hline 0.90 & $0.14 * * *$ & $0.646^{* * * *}$ & $0.128 * * *$ & $0.775 * * *$ & $0.066^{* * *} *$ & 0.972 \\
\hline QKS & $3.653(0.006)$ & & $6.260(0.00$ & & $1.556(0.90$ & \\
\hline
\end{tabular}

The smallest $t$ value, 0.10 , represents the lowest negative shock, whereas 0.9 represents the highest positive shock. $* * *$ and $* * *$ represent significance at 10,5 and $1 \%$, respectively 
For the $\alpha_{1}$ estimates of Raw Materials exports, which have the largest share of total exports based on the BEC classification, we reject the null of the unit root for the 60th to 90th quantiles but we cannot reject the unit root for lower quantiles. This result implies that Raw Materials exports show persistent behaviors when hit by negative shocks. For Investment Goods, we cannot reject the null of the unit root for all quantiles. For negative and positive shocks, Investment Goods exports display persistent behavior. For Consumption Goods exports, we reject the null of the unit root for higher and lower quantiles but not for middle quantiles. The asymmetric behavior of Consumption Goods can be explained by consumers' changing behaviors, for example, if foreign demand falls due to slowdowns in the economies of Turkey's trading partners, foreign consumers might behave more cautiously. From the producers' perspective, a similar argument could be made for Raw Materials.

To summarize, based on the BEC export classification, while Raw Materials and Consumption Goods exports do not have a unit root at higher quantiles, Investment Goods exports in each quantile show a persistent behavior. The results of Raw Materials exports are found to be parallel to the results of Food and Beverages, Chemicals and Basic Metals exports, and the results of Investment Goods exports are parallel to the results of Fabricated Metals, Textiles and Apparel exports.

Overall, our results suggest that not all export types are uniform in their unit root properties. Exported products are partly durable goods and contrast non-durable goods, and particularly, consumption goods contrast investment goods. Based on their characteristics and the groups to which they belong, export types' behavior and volatility may change under different situations. For instance, we expect that in the case of an unfavorable development, consumers would postpone their durable goods consumption rather than their non-durable goods consumption (e.g., Food and Beverages) and durable goods would have a more volatile structure. Moreover, negative shocks might have different implications for Consumption Goods versus Investment Goods; the first response would likely come from the former. The duration of the shock for Investment Goods would also be affected by the duration of the shock for Consumption Goods because the latter sector represents the demand factor of Investment Goods. Therefore, timing, the nature of the shock and the export sector constitute vital factors that should be explored by economic policy makers to influence export strategy. In this respect, solely focusing on exports' average behavior by using standard unit root tests does not allow elaborating on export dynamics, which can lead to misleading results. Thus, we believe that Turkish (and all) policy makers might be interested in concentrating on a quantile autoregression unit root method as a guidance instrument for export policies because it emphasizes export sustainability and increasing added value to help ensure a stable growth path.

\section{Conclusion}

Turkey liberalized its international trade in the first half of the 1980s. Since then, exports have become an increasingly important contributor to the country's economic growth and its export policy has become an important issue. Export 
dynamics have attracted a significant amount of attention from academics and policy makers in their efforts to ensure sound export strategies and sustain export performance. Considering the importance of this issue in the Turkish economy, this paper conducts an empirical analysis of the persistence of export shocks to disaggregated exports (ISIC Rev.3 and BEC classifications) using monthly data covering the period 1996:1-2012:4. The analysis is based on testing the unit root by the QAR methodology, which allows assessing the unit root properties of export components across different shock magnitudes.

Although traditional unit root tests cannot reject the null of the unit root in almost all the series we consider, our empirical analysis based on the QAR method suggests different results for disaggregated export sectors regarding the persistency of shocks in different quantiles. First, parallel to conventional unit root tests, for the traditional Turkish export sectors of Textiles and Apparel, for each quantile the unit root cannot be rejected. This result implies that negative and positive shocks would have persistent impacts on these export sectors. The same result is also found to be valid for Fabricated Metals and Investment Goods exports and for Machinery and Equipment exports, except for the first quantile.

For Total Exports, Food and Beverages, Chemicals, Basic Metals and Raw Materials exports, negative shocks have a persistent behavior, which would lead to a market loss in these sectors unless specific policy measures were taken to prevent adverse effects. When these sectors are subject to positive shocks, the system is mean-reversing. According to the estimation results, Consumption Goods exports do not have a unit root except for the 30th and 40th quantiles.

Our estimation results show that for Motor Vehicles exports, which is a pioneering sector, the unit root cannot be rejected at higher quantiles but can be rejected at lower quantiles, implying that a negative shock is not persistent whereas a positive shock is persistent. These results suggest that in the event of a negative shock to the sector, Motor Vehicles exports would pick up. Moreover, any positive shock would mean an increase in the sector's share in world markets and would be persistent.

Our results provide significant policy implications. Their macroeconomic interpretation supports that exports at the disaggregated level display different behaviors when exposed to negative or positive shocks. While some shocks can have persistent impacts, others can have temporary effects. Hence, one policy for all exports would not generate desired results. Different sectors and different shocks require different policy actions, and policy makers should consider this factor when pursuing an export strategy.

In the last decade, Turkish exports have increased significantly and evolved from a labor-intensive to a more medium-technology structure. However, Turkey's high import dependency of exports, the concentration of Turkish imports in the low- to medium-value-added segment of the global value chain, and the country's very small share of high-tech exports in total exports are still key challenges to achieving the 500-billion-dollar export target stated in the government's 2023 Vision. To achieve this target, Turkey has been promoting high-value-added exports in contrast to import-dependent exports. In other words, in high-value-added sectors, it is better that shocks be persistent at higher quantiles. Thereby, exports will be promoted and 
the contribution of exports to the economy will be larger. On the other hand, mean reversion is better at lower quantiles so that when the sector is hit by an adverse shock, it will be mean-reverting. The empirical evidence reported in this paper suggests that Machinery and Equipment as well as Motor Vehicles fit this category. Thus, in order to increase export performance and hit the 2023 Vision goal, these two sectors might be promoted. On the other hand, in high-value-added sectors, a set of technologies or a market structure can be adopted that would enable positive shocks to be more persistent (at higher quantiles) but negative shocks to be meanreverting (at lower quantiles). In this way, in addition to Machinery and Equipment and Motor Vehicles, other sectors that would improve Turkey's export performance to achieve the 2023 Vision would be created.

Acknowledgments We would like to thank Rana Nelson for her helpful suggestions.

\section{References}

Berument MH, Dincer N, Mustafaoglu Z (2014) External income shocks and Turkish exports: a sectoral analysis. Econ Model 37:476-484

Bircan C, Koc M (2012) Aflatoxins in dried figs in Turkey: a comparative survey on the exported and locally consumed dried figs for assessment of exposure. J Agric Sci Technol 14:1265-1274

Boengiu T, Triandafil CM, Triandafil AM (2011) Debt ceiling and external debt sustainability in Romania: a quantile autoregression model. J Econ Forecast Inst Econ Forecast 4:15-29

Campbell JC, Perron P (1991) Pitfall and opportunities: what macroeconomists should know about unit roots. NBER Macroecon Annu 6:141-220

Dincer N, Kandil M (2011) The effects of exchange rate fluctuations on exports: a sectoral analysis for Turkey. J Int Trade Econ Dev 20(6):809-837

Gomes FAR (2011) Testing the permanent income hypothesis using unit root quantile autoregression tests. Appl Econ Lett 18:1755-1758

Hoffmann R, Ging LC, Ramasamy B (2003) Shocks to Malaysia's exports: temporary or permanent? J Asia-Pac Bus 5(1):19-31

Islam MN (1998) Exports expansion and economic growth: testing for cointegration and causality. Appl Econ 30:415-425

Koenker R, Bassett G Jr (1978) Regression quantiles. Econometrica 46(1):33-50

Koenker R, Xiao Z (2002) Unit root quantile autoregression with applications on asymmetric business cycle dynamics. Working paper, University of Illinois at Urbana-Champaign

Koenker R, Xiao Z (2004) Unit root quantile autoregression inference. J Am Stat Assoc 99:775-787

Koenker R, Xiao Z (2006) Quantile autoregression. J Am Stat Assoc 101:980-990

Kónya L (2004) Unit-root, cointegration and granger causality test results for export and growth in OECD countries. Int J Appl Econom Quant Stud 12:1-28

Lim SY, Chia RC, Ho CM (2011) Long-run validity of export-led growth: an empirical reinvestigation from linear and nonlinear cointegration test. Econ Bull 30(2):1182-1190

Mangir F (2012) Export and economic growth in Turkey: cointegration and causality analysis. Econ Manag Financ Mark 1:67-80

Ozturk I, Acaravci A (2010) Testing the export-led growth hypothesis: empirical evidence from Turkey. J Dev Areas 44(1):245-254

Perron P, Vogelsang TJ (1992) Nonstationarity and level shifts with an application to purchasing power parity. J Bus Econ Stat 10:301-320

Tsong CC, Lee CF (2011) Asymmetric inflation dynamics: evidence from quantile regression analysis. J Macroecon 33:668-680 